\title{
James Thompson, un viajero británico en México
}

Abrabam Téllez

IMEP

Para Ana María y Alberto

$\mathrm{E}$

n el último decenio del siglo xviII y en el primero del siguiente, surgieron en la Gran Bretaña diversas asociaciones interesadas en distribuir la Biblia y extractos de ella a precios módicos, primero en las islas británicas y más adelante en otras partes del mundo. ${ }^{1}$ Dichas asociaciones eran ecuménicas, es decir que participaban en ellas diversas denominaciones protestantes cuyo objetivo final era la distribución de la Biblia sin tomar en cuenta interpretaciones particulares. Buscaban extender el conocimiento y el estudio de las escrituras, sobre todo en aquellos lugares en donde otra u otras religiones eran mayoria, como en Asia, África y Oceanía.

'Mckechnic, “Mexican”, 1970, pp. 18-19.
Años más tarde, dicho interés se trasladó a otras regiones, como América Latina, donde la Biblia era poco leída por el pueblo debido, en parte, a que entre las sociedades católicas no se acostumbraba esta lectura (por el alto índice de analfabetismo, por la falta de ejemplares, o bien por tener éstos un precio muy elevado).

Esta intención de difundir la Biblia surgio aparejada con la idea de instruir a la población en el arte de la lectura, y con la misión cristiana de la predicación por parte de aquellas personas que llevaban la Biblia -los colporteurs (agentes bíblicos)-a diversas partes del globo. De este modo, en 1795 se fundó la London Missionary Society (LMS). 
Los antecedentes más remotos dentro de la Gran Bretaña se encuen. tran en 1642, cuando Thomas May. hew fundó una misión para los indios en Marthas's Vineyar y poco más tarde con la pléyade de misioneros que siguieron sus pasos, sobre todo su propia familia y John Eliot; ${ }^{2}$ posteriormente, en 1702, se creó una Sociedad Misionera "para la propagación de los evangelios en tierras extranjeras", sólo que esas "tierras extranjeras" se limitaban a sus propias colonias. Aun así, esta Old Missionary Society reflejaba el interés de los británicos por llevar organizadamente su fe religiosa a lugares lejanos. ${ }^{3}$

El principal promotor de la LMS fue William Carey, ${ }^{4}$ quien estaba con. vencido de que era responsabilidad cristiana llevar el conocimiento de la Biblia a todas partes. Para apoyar los trabajos emprendidos por Carey se formó, en 1792 , una Sociedad Británica Bautista, antecedente de la LMS. Más tarde, en 1799 , se estableció la Church Missionary Society, gracias a los empeños de un grupo denominado Chapham Sect. Esta secta cristiana fue fundada en 1790 y estaba formada por hombres prominentes de la sociedad inglesa -algunos miembros del gobierno- quienes lup. 126.

2 Ortega y Medina, Evangelización, 1976,

3 Dunstan, Protestantism, 1961, p. 176.

4 Hastings, History, 1956, p. 308. Este autor nos dice que William Carey tomo esta idea de misión a partir de la lectura del libro de John Eliot y David Brainerd sobre los indios de Norteamérica y del libro Voyages of captain Cook. Véase también la Encylopaedia Britannica, vol. a, p. 865, para una biografia completa de William Carey. chaban entre otras cosas por la abolición de la esclavitud, por reformas penitenciarias, por la eliminación de deportes crueles, por la prohibición de los juegos de azar y, además, apoyaban la distribución de la Biblia entre las clases proletarias. ${ }^{5}$

En 1804 esta misma secta estableció y organizó, junto con otras organizaciones, la British and Foreign Bible Society (BFBS). Ésta fue la primera sociedad bíblica en el mundo, y de ella tomarian ejemplo, en cuanto a propósitos y organización, todas las sociedades de esta naturaleza que se formarían en el futuro en Europa y Estados Unidos.

La mayoria de quienes pertenecian a la BFBS también participaban en los trabajos de la Sociedad Lancasteriana de Inglaterra, que años después se convertiría en la British and Foreign Schooll Society (BFss, 1810) y que tenía por objetivo la difusión del sistema educativo inventado por Joseph Lancaster, en el cual se usaba la Biblia como libro de lectura. Así, no es de extrañar que ambas sociedades compartieran, además de los miembros, el mismo interés por distribuir y enseñar a leer la Biblia. ${ }^{6}$

5 Encyclopaedia Britannica, 1982, vol. III, p. 344 .

6 "La Sociedad Bíblica Británica y Extranjera tomó para sí no sólo la responsabilidad de iniciar en Inglaterra los métodos de Lancaster, sino, sabiendo la gran necesidad de esta instrucción en otros países, especialmente en la América Hispánica, decidió enviar sus representantes hacia dicho continente con el proposito de establecer escuelas. En vista de la tendencia especial de la enseñanza en todas las escuelas bajo este sistema, debido al deseo expreso del rey de que cada alumno debería ser enseñado a 
Es en este contexto donde debemos ver la obra que James Thompson realizó en diferentes países de América Latina -y particularmente en México-, al recorrer prácticamente todo el continente con la doble misión de educador y de colporteur, en representación de las dos sociedades británicas antes mencionadas. ?

James Thompson nació en Escocia en 1788 e hizo sus estudios ministeriales en el Seminario Teológico de Glasgow. Una vez ordenado ministro, se encargó de una congregación al sur de Escocia, en un lugar llamado Douglas Town. Thompson marchó a la ciudad de Londres y alli entró en contacto con la BFBS y con la BFSS, y decidió incorporarse a ellas como agente bíblico y educador. Al término de su preparación, ambas sociedades decidieron enviarlo a Sudamérica.

James Thompson arribó a Buenos Aires el 6 de octubre de 1818 y per-

leer la Biblia, no es extraño que la Sociedad Lancasteriana unificara sus esfuerzos con los de la BFas y que estas dos sociedades delegaran su representación al mismo hombre. James Thompson, un escocés, fue el hombre elegido para representarlas en la América Hispanica." Browning, "Lancaster", 1921, pp. 62-63. Para una biografia completa de Lancaster, véase Encylo. paedia Britannica, 1982, vol. vI, pp. 131-132.

7 "Thompson era un bautista escocés que había ejercido el cargo de párroco, se había dedicado al estudio del castellano y del método pedagógico del cuáquero J. Lancaster, que por entonces se consideraba revolucionario y que se apoyaba en gran medida en la lectura de textos bíblicos sin comentarios. Siendo secretario de la Bfss y de la Traslation Society, Thompson se hizo enviar por la bfBs a América Latina, donde inció su labor en 1818 en Buenos Aires. Dondequiera que fundo una escuela, introdujo la lectura de la Biblia en clase." Prien, Historia, 1985, p. 714 . maneció en esas latitudes hasta mayo de $1821 .^{\circ}$ El gobierno argentino, ente. rado de su misión, le invitó a establecer y a dirigir escuelas bajo el sistema lancasteriano. La Gaceta de Buenos Aires del 15 de noviembre de 1820 nos informa que
para que los progresos de la institución y de la educación sean más rápidos y eficaces, al mismo tiempo que más sen- cillos, el Cabildo ha acordado estable- cer todas las escuelas bajo el mismo plan de mutua enseñanza del señor Lancaster, que con los más felices efec- tos está generalmente establecido en Europa. Con este objeto ha puesto es- tos establecimientos bajo la dirección de Diego Thompson, que conoce muy bien a fondo este sistema, y a quien ha nombrado director general de todas ellas, tanto en la ciudad como en las provincias. 9

Thompson organizó en Buenos Aires ocho escuelas, además de que viajó por la provincia vendiendo y repartiendo biblias; fue también a Montevideo, donde fundó otra escuela. Hay que apuntar que Thompson llevaba también la misión de investigar las condiciones mediante las cuales se podría fomentar la inmigración británica. ${ }^{10}$

En febrero de 1821 se organizó en Buenos Aires la Sociedad Lancasteriana para continuar promoviendo la educación una vez que Thompson decidiera partir.

Poco antes de su salida a Chile, el

${ }^{8}$ Goslin, Evangélicos, 1956, p. 17.

9 Varetto, Héroes, 1958, p. 161.

10 Goslin, Evangélicos, 1956, p. 18. 
Cabildo de Buenos Aires reconoció la labor hecha por Thompson en favor de la niñez de la ciudad, ortorgándole el título de ciudadanía. Posteriormente, el 29 de mayo de 1821, el gobierno hizo lo propio y le dio la carta de naturalización.

A mediados de 1821 viajó a Santiago, la capital de Chile, país que lo había contratado por medio del representante chileno para que realizara en ese país andino labores semejantes a las efectuadas en Argentina. Ahí organizó rápidamente tres escuelas, una especial para la formación de maestros que en el futuro serían enviados a diversas zonas del país. En Chile intentó promover la inmigración de súbditos británicos, pero se encontró con una fuerte presión del clero, que se opuso rotundamente alegando "que la venida a Chile de familias extranjeras (no católicas) arruinaría la religión católica". 11

Al cabo de un año en el país austral, y de un trabajo con no pocos obstáculos, Thompson decidió abandonarlo y buscar nuevos horizontes; antes de su partida, en un decreto firmado por el general O'Higgins el 31 de mayo de 1822 se le declaró ciudadano chileno en agradecimiento por sus trabajos educativos.

En junio de 1822 el escocés partió con destino a Lima, donde fue recibido por el general San Martín, quien le prometió apoyo en su labor educativa $y$, pasando de las palabras a los hechos, emitió un decreto ( 6 julio 1822) en el que, después de dar un reconocimiento a la educación y al

11 Westrup, Paladines, 1953, p. 126. sistema lancasteriano, acordaba, entre otras disposiciones, establecer una escuela central basada en los principios lancasterianos bajo la dirección de James Thompson.

En Perú se encontró con gran cantidad de indígenas que prácticamente no hablaban español, siendo el quechua su medio de comunicación. Ante ello, Thompson se dio a la tarea de buscar personas conocedoras de este idioma para que tradujeran algunos pasajes de la Biblia; se sabe que un ofcial del ejército peruano entró a la escuela central para colaborar en la tarea de traducción. ${ }^{12}$

Las condiciones políticas en Perú no eran nada apacibles, por ello decidió continuar su viaje más al norte. En septiembre de 1824 salí con rumbo a Guayaquil, y después a Quito, donde vendió y repartió material bíblico. Es de notar que hasta su estancia en Lima, Thompson dio gran importancia a su tarea como educador, pero de ahí en adelante se concentró más en su trabajo de colporteur, ${ }^{13}$ esto es: prefirió dedicarse de lleno a la distribución y venta de material bíblico. Es posible que esto se debiera a que tenía en mente regresar lo antes posible a Londres para informar perso. nalmente de sus labores a ambas sociedades, y el hecho de organizar escuelas hubiera retardado su regreso. Sin embargo, esto no quiere decir que se haya despreocupado de su labor educativa, ya que en las ciudades por donde pasó procuró dar a conocer las bondades del sistema lancasteriano,

12 Goslin, Evangelicos, 1956, p. 19.

13 Browning, "Lancaster", 1921, p. 89. 
aunque sin adquirir el compromiso de implantarlo en las escuelas.

De Quito partió a Bogotá, donde llegó a principios de 1825. En marzo de ese año fundó, junto con ilustres colombianos, la Sociedad Bíblica Colombiana, en la que participaron el ministro de Relaciones Exteriores (quien aceptó el cargo de presidente) y el de Hacienda, el vicepresidente de la república y algunos sacerdotes. El propósito de esta sociedad fue "publicar y distribuir las Santas Escrituras en español". Ésta fue la primera sociedad bíblica en América Latina, y funcionó hasta 1835 , año en que Colombia obtuvo el reconocimiento diplomático del Vaticano $y$, por conveniencia política, decidió clausurar la Sociedad. ${ }^{14}$

Después de la fundación de la Sociedad, Thompson abandonó Bogotá con rumbo a Londres, donde llegó a mediados de 1825, después de permanecer casi siete años en Sudamérica. Se desconocen los términos exactos en que Thompson informó a las sociedades acerca de sus logros en los países por él visitados, pero es muy probable que ambas instituciones quedaran gratamente sorprendidas por la labor tan sustancial que su enviado había efectuado en las jóvenes repúblicas.

Actualmente James Thompson es recordado en casi todas éstas como un precursor de los sistemas educativos y, por otro lado, es ponderado por los protestantes de nuestro continente como el gran impulsor de la causa bíblica en América Latina.

14 Prien, Historia, 1985, p. 713.

\section{JAMES THOMPSON EN MÉXICO}

El reverendo Thompson regresó a Inglaterra en 1825. Al año siguiente, en 1826, la BFBs decidió excluir de sus biblias los libros llamados apócrifos. Esta decisión trajo como consecuencia un rompimiento con el resto de las sociedades bíblicas europeas que no acep. taron de buen grado esta resolución unilateral, ${ }^{15}$ la cual traería nuevos problemas a los colporteurs cuando dichas biblias llegaran a América Latina, pues la jerarquía católica las desautorizaría para su distribución tomando como pretexto la falta de dichos libros; en su momento, también le causaria dolores de cabeza a Thompson al intentar distribuirlas en nuestro país.

Suponemos, con algo de certeza, que durante 1826 Thompson se ocupó en preparar para su publicación un libro titulado Letter on the moral and religious state of South America, written during a residence of nearly seven years in Buenos Atres, Cbile, Peru and Colombia, publicado por James Nisbet en Londres y que apareció en enero de 1827. Este texto es conocido en español simplemente como "Las cartas de Thompson", que son precisamente una recopilación cronológica de los escritos que el reverendo enviaba descle los lugares donde trabajaba. En el prefacio de esta obra dice estar a punto de embarcarse a México como agente de la bFBs, llevando consigo un número considerable de biblias en español y, además,

15 Encylopaedia Britannica, 1982, vol. II, p. 527. 
la misión de procurar que fueran traducidas a las distintas lenguas nativas que, él cree, son habladas todavía por millones de indigenas. ${ }^{16}$ En dicho prefacio nada dice acerca de sus futuros trabajos como enviado y representante de la BFSs, mas debemos suponer que también tenía esa representación, pues se ocupó de fundar y dirigir por lo menos una escuela en México. Sin embargo, se puede inferir que su principal preocupación fue su trabajo como colporteur. No hemos encontrado datos que nos permitan conocer si se ocupó de alentar la inmigración británica a México.

¿Por qué razón decidieron enviar a Thompson? Sin duda fue determinante para ambas sociedades la experiencia previa del reverendo en Sudamérica, su magnífico conocimiento del idioma español, pero además pensamos que la iniciativa pudo venir de don Vicente Rocafuerte, principal colaborador de Mariano Michelena, encargado de negociar en Londres el reconocimiento de México y un tratado de amistad. Rocafuerte había colaborado con la Sociedad Bíblica Americana y con la Free School Society de Nueva York para promover la educación lancasteriana en Hispanoamérica, y sabemos, gracias a una misiva, que por lo menos desde 1825 compraba biblias a la BFBS para ser enviadas a México, y por la familiaridad de la misma, podemos colegir que existía una relación previa; ${ }^{17}$ además, tuvo

16 Goslin, Evangélicos, 1956, p. 17.

17 Carta de Vicente Rocafuerte a J. J. Jackson, Archivo de la British and Foreign Bible Society (BFBS), FC, 1925, p. 152. gran interés en que la BFss estuviera presente con una ponencia en el Congreso Panamericano de Tacubaya; incluso entre ambos prepararon un escrito titulado Representación de la Socledad Británica y Extranjera de Escuelas Mutuas al Congreso de Tacubaya (Londres, 1827). ${ }^{18}$

Thompson salió de Inglaterra en abril de 1827 y arribó al puerto de Veracruz el 2 de mayo. De inmediato se trasladó a la capital, donde llegó el día 17 , y enseguida comenzó a preparar letreros anunciando la venta pública de biblias. Antes de iniciarla, el reverendo encontró en una librería capitalina gran cantidad de biblias que com. pró para venderlas días más tarde. ${ }^{19} \mathrm{El}$

18 Rocafuerte "convencio a la BrBs que propusiera un plan de desarrollo de la educación hispanoamericana a la Segunda Conferencia Panamericana, que tendría lugar en Thcubaya (México) en 1827. luego colaboró con James Thompson, designado representante de la Sociedad, en la preparación del manifiesto oficial al Congreso de Tacubaya. Thompson partió con rumbo a México en febrero de 1827 , llevando consigo varias cajas de biblias $y$ numerosos ejemplares del manifiesto de la Sociedad, llegó a Veracruz el 29 de abril [...] Desgraciadamente, esta reunión panamericana no fue celebrada, por lo cual no pudo ser estudiada la proposición de la BfBs, pero Thompson permaneció de todos modos en México". Rodríguez, Nacimiento, 1980 , pp. 241-242.

19 "Algunos días después llegó a la capital (procedente de Veracruz), donde por suerte en una librería encontro y compró algunos cajones de biblias que no se habían vendido por carecer de los libros apócrifos. Posiblemente habían sido mandados por el doctor Brigham." Este doctor Brigham no es otro que un comisionado de la Sociedad Bíblica Americana de Nueva York, quien había visitado nuestro país entre 1824 y 1826 trayendo algunas biblias. También tenemos noticias de que entre 1826 y 1827 unos señores llamados Parrot y Wilson habían traído 


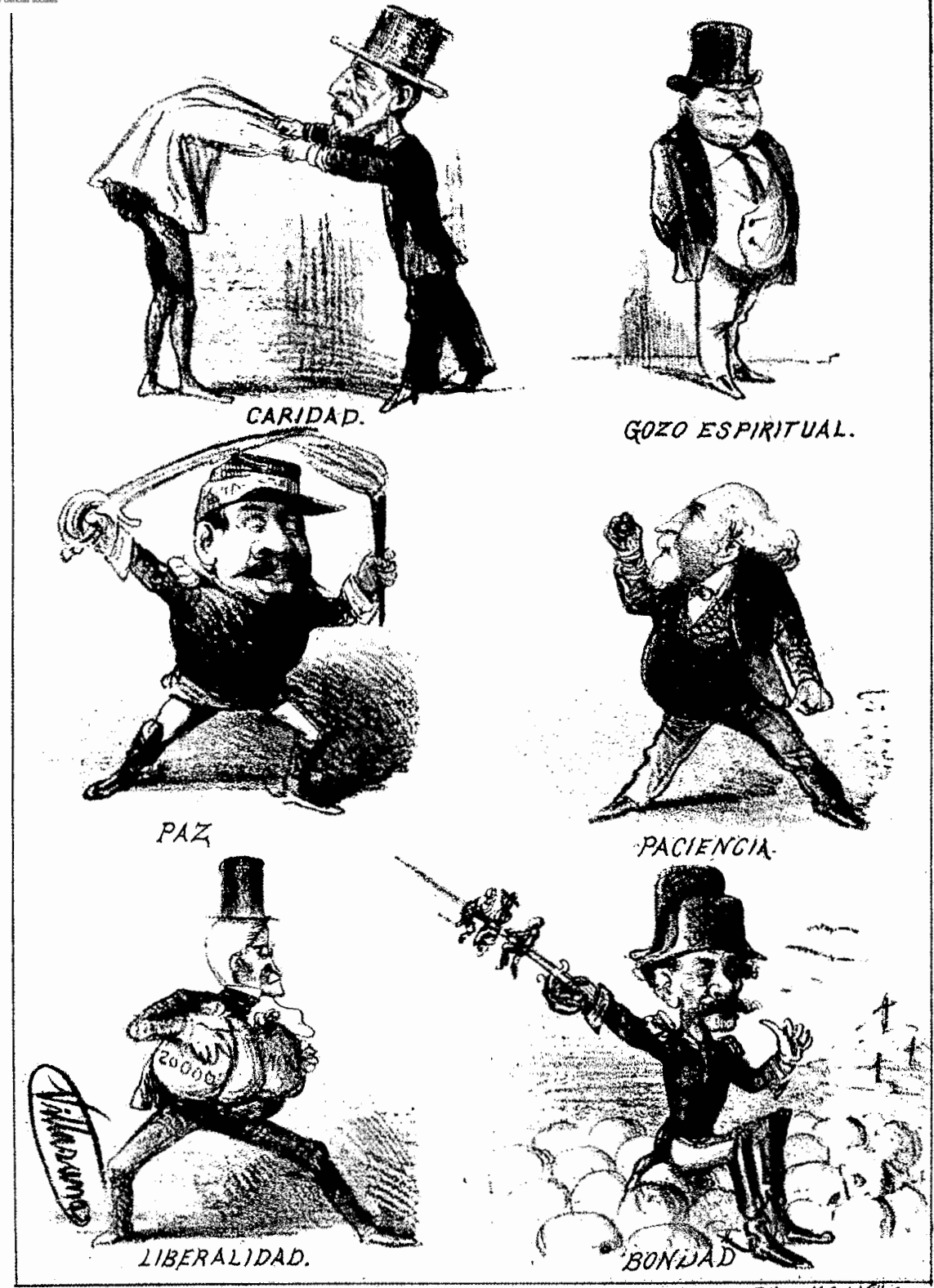

Los frutos del "Espiritu de ta época."

Editor:M.C.de Hilleges. 
13 de septiembre de 1827 apareció un anuncio en el diario $E l$ Sol que ofrecía biblias, nuevos testamentos y literatura; podemos inferir que el responsable de dicho anuncio fue James Thompson.

Entre mayo y septiembre, seguramente con ayuda de Rocafuerte, logró relacionarse con diversas personas, entre ellas el rector del Colegio de San Agustín, padre don José María Alcántara, y con el padre don José Antonio López García de Salazar; ambos aceptaron suscribirse a la BFBs. Más adelante entró en contacto con el doc. tor José María Luis Mora, de quien informo "lo hallé con muy amistosa disposición hacia la Sociedad Bíblica".20 Mora pasó también a ser suscriptor. En ese año de 1827, el doctor Mora era director de $E l$ Observador de la República Mexicana; posteriormente sería el encargado de los intereses de la BFBS en México.

A mediados de 1828 algunos periódicos de la ciudad, enterados de la labor que realizaba el reverendo Thompson, empezaron a criticar la distribución de biblias debido a la falta de los apócrifos antes mencionada. Las biblias que Thompson tenía consigo y las que había comprado, eran traducción del padre Scío de San Miguel, autorizada por la Iglesia católica. Como ya se dijo, hasta 1826 las biblias editadas en español por la BFBs contenían los apócrifos, habiendo sido tirados 10000 ejemplares de ellas entre 1821 y 1824 . Cuando Thompson salió de Londres ya estaba agotada esa

biblias por parte de la Sociedad Bíblica Americana. Goslin, Evangélicos, 1956, p. 23.

${ }^{20}$ Báez Camargo, Mora, s. a., pp. 9 y 20. edición y, por tanto, las que él traía consigo ya no incluían los libros en cuestión, que era el punto negativo a que los diarios se referían. ${ }^{21}$

Las autoridades católicas, al tener conocimiento de este asunto, decidieron emitir un edicto eclesiástico que prohibía a los fieles aceptar tales biblias, sólo que esto fue hecho hasta julio de 1828. Thompson, sin saberlo, había llegado a nuestro país en un momento muy oportuno para él y para su trabajo, ya que la Iglesia católica se encontraba en proceso de reacomodo dentro de las nuevas circunstancias políticas. 22 Tal vez por ello la tarea de Thompson sólo comenzó a ser seriamente obstaculizada al año de su llegada. Ningún otro personaje lograría actuar en lo sucesivo con la "libertad" con que lo hizo Thompson (a pesar del edicto); sólo hasta muchos años más tarde, cuando se respiraban en México los aires de la libertad de cultos.

En 1827 Thompson decidió realizar un periplo por el interior de México. Así, partió rumbo a Querétaro, Celaya, Guanajuato, San Juan de los Lagos, Aguascalientes, Zacatecas, San Luis Potosí y, al agotársele su cargamento de biblias, regresó a la capital a comienzos de 1828. Esperó a tener una nueva remesa de literatura bíblica y emprendió otro recorrido, en esta ocasión por Puebla, Tlaxcala, Veracruz y Oaxaca. En mayo de ese año, en la ciudad de Orizaba y con la colaboración de José Joaquín Pesado,

21 Ibid., p. 10, véase también Macín, Lutero, 1983 , p. 40.

22 Staples, Iglesia, 1976, pp. 11, 162. 
formó una sociedad bíblica local, la cual se comprometió a distribuir las biblias en Córdoba y Chalchicomula.

En Puebla su labor rindió excelentes frutos, ya que el mismo obispo del lugar, por conducto de Thompson, remitió una carta a Londres expresándose en términos muy cordiales de la BFBs. ${ }^{23}$

El edicto contra la distribución de biblias no lo hemos podido localizar, pero por el propio Thompson sabemos lo siguiente:

A poco de mi llegada [se refiere a su segundo viaje al interior] una tempestad se desencadenó, la cual había sido iniciada algunos meses atrás. La tempestad a la cual me refiero fue una molesta oposición en forma de edicto en contra de la compra, venta, lectura o posesión de las biblias editadas por la Sociedad. El mencionado edicto publicado por el dean y chapter (capítulo) de la diócesis metropolitana de México, afectó grandemente la circulación de las Escrituras. Este edicto fue pronto seguido por otros similares en la diócesis de Oaxaca y en la de Guadalajara. Estos edictos no sólo afectaron la circulación de la Escrituras en las diócesis respectivas en donde ellos tenían efecto legal, sino que su influencia abarcó gran parte del país. ${ }^{24}$

A partir de este momento, la labor del reverendo comenzó a encontrar barreras cada vez más difíciles de superar, puestas incluso por autoridades civiles. Empero, amistades cerca-

${ }^{23}$ Báez Camargo, Mora, s. a., pp. 11-13. dice).

${ }^{24}$ Gandee, "Introduction", 1949, p. 64 (apén-

JAMES THOMPSON, UN VIAJERO BRITÁNICO EN MÉXICO 


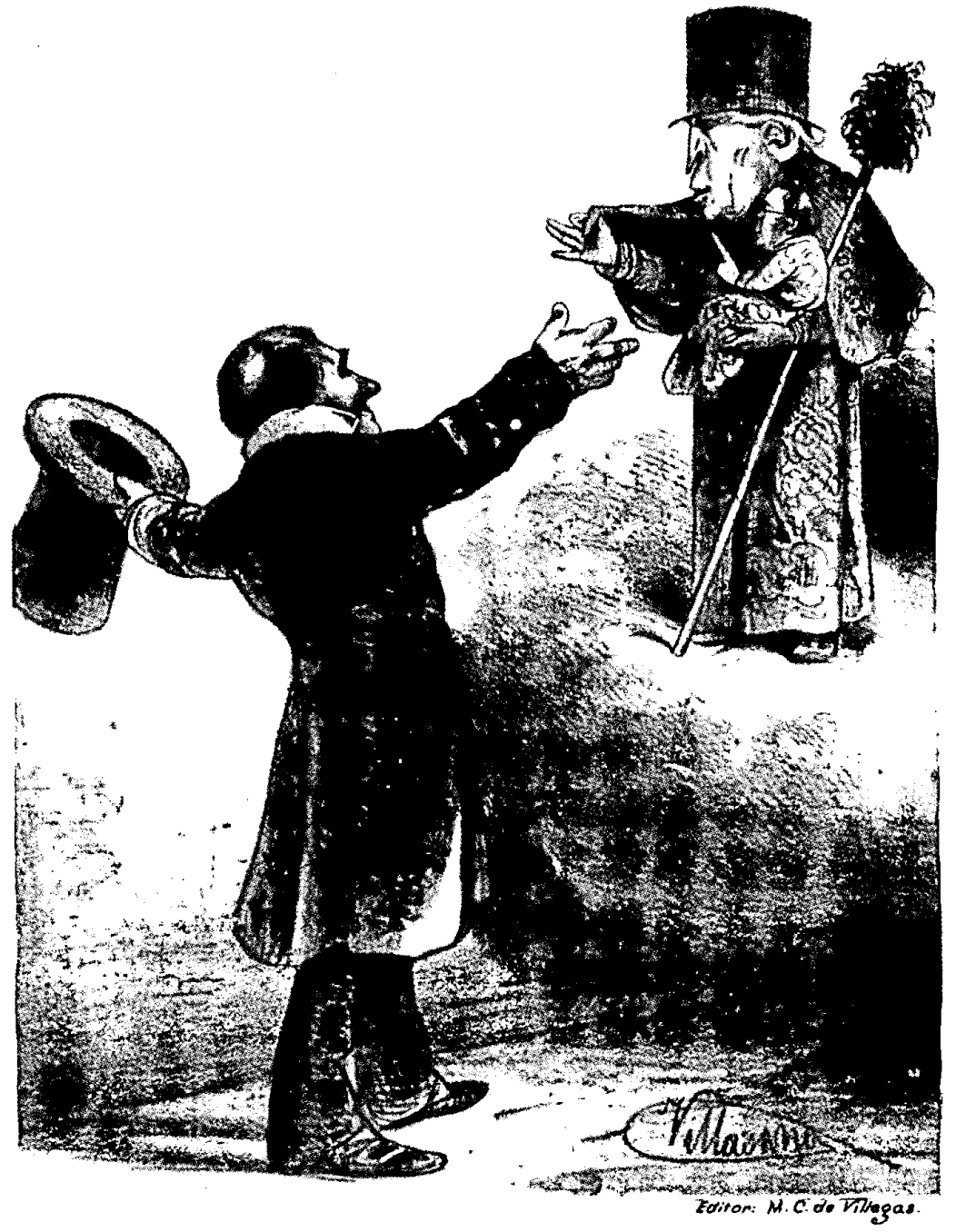

- Señor, bajo tu manto nos acogimos.......

- Amigomio. V. cree que es capa y no escapa. 
permaneció al tanto de los negocios de la BFBS en México hasta su muerte, ocurrida en 1850 en París.

A pesar de las buenas relaciones que Thompson hizo en México, particularmente las amistades de Rocafuerte y Mora, no le fue posible evitar la influencia del clero y poco a poco su actividad misionera languideció. Hizo todavía un último intento al apelar a los tribunales civiles la disposición eclesiástica de prohibir la venta de biblias, pues la aduana se había negado a entregarle un cargamento que se encontraba en Veracruz, y ni con la intervención del representante inglés se pudo lograr algo efectivo. Ante ello decidió acudir a Vicente Rocafuerte, y éste escribió (mayo de 1830) al ministro Lucas Alamán pidiéndole que intercediera en favor del reverendo. Empero su petición no prosperó y esto acabó por desalentar completamente a Thompson. ${ }^{28}$

Vicente Rocafuerte hizo en 1831 una mención acerca de la labor de Thompson como educador en la ciudad de México. Dijo que

un caballero inglés llamado Mr. Thompson estableció en la calle del Ángel una escuela para niñas: llegó a tener hasta 45 discípulas, a quienes enseñaba el inglés, la geografia, la historia, la aritmérica, y a escribir con elegancia y correcta ortografia. Mr. Thompson, por su perfecto conocimiento de la lengua castellana, por sus virtudes y talentos cultivados, era el sujeto más a propósito para haber generalizado entre nosotros la educación del bello sexo, que tanta falta nos hace; pero tales fueron los dis-

28 Rocafuerte, Revoluciones, 1962, p. 230. gustos que tuvo y tal la falta de protección de parte del Ministerio, que se vio precisado a regresar a su tierra con el pesar de ver el poco aprecio que se hace aquí del mérito personal y de las ventajas de una buena enseñanza. ${ }^{29}$

Esta noticia de Rocafuerte es la única que tenemos para certificar que efectivamente Thompson sí hizo por lo menos este trabajo en representación de la BFSS, y que lo hizo en favor de las niñas.

Thompson decidió salir de la capital el dia 5 de junio hacia Veracruz, al considerar que su presencia ya no era útil y que por el contrario quizás representaba un obstáculo para la distribución de la literatura bíblica. Confiaba en que Robert P. Stables (librero que había aceptado ser distribuidor a comisión) podría continuar con esta labor, y además el doctor Mora se encargaría de los asuntos de la Sociedad en México. ${ }^{30}$

Finalmente salió de la república mexicana el día 19 de junio de 1830 con rumbo a Nueva Orleans. Más adelante ofreció a la BFBS trabajar en las Antillas mayores y menores, $y$ fue a las islas repartiendo las Escrituras; su actividad principal la hizo en Cuba, donde

29 "A pesar de los problemas que Thompson tuvo, su trabajo como colporteur fue en realidad excelente. El reporte de la BfBS del año de 1829 indica que fueron enviadas a México 3200 biblias; 4200 nuevos testamentos; 1000 porciones, conteniendo cuatro libros del Antiguo Testamento; 3000 evangelios según San Lucas, con el libro de los Hechos de los Apostoles." Gandee, "Introduction", 1949, p. 70; véase también Rodríguez, Nacimiento, 1980, pp. 256. 257.

${ }^{30}$ Báez Camargo, Mora, s.a., p. 20. 
logró establecer un depósito y centro de ventas. Sin embargo, lo detuvieron, le confiscaron las biblias y le ordenaron salir de la isla. Recordando su labor en las Antillas, en 1837 Thompson escribió a un amigo de la Sociedad que en todas las islas su labor había prosperado menos en Puerto Rico, donde no se le permitió realizar ninguna actividad. ${ }^{31}$

De Cuba regresó a Inglaterra a informar de sus actividades; posteriormente fue destinado a viajar a $\mathrm{Ca}$ nadá, donde pasó dos años en sus acostumbradas labores. La Sociedad le encomendó viajar a México de nueva cuenta y realizar otra vez su labor en pro de la circulación de la Biblia. Thompson aceptó y arribó a tierra me. xicana en agosto de 1842.32 Ya en la ciudad de México, observó que la circulación de biblias era notoria, en parte debido a su labor precedente y en parte a que el clero mexicano habia impreso una edición en versión del padre Mariano Galván. Decidió tratar de publicar una edición del Nuevo Testamento de la versión de Galván para introducirla en las escuelas como libro de lectura, pero en ambas tareas fracasó. Ante ello, en octubre de 1843 decidió viajar a Yucatán, al parecer invitado por un importante político, quien deseaba que Thompson organizara una reforma educativa y que tradujera la Biblia al maya. ${ }^{33}$ Por aquel entonces la Constitución de Yucatán lo permitía ya que el Congreso, brotado de la revolución yucateca, reformó la Constitución local (31 de marzo de

31 Browning, "Lancaster", 1921, p. 97.

32 Gandee, "Introduction", 1949, p. 72.

33 Mckechnic, "Mexican", 1970, p. 23.
1841) e inició la reforma religiosa, proclamando la libertad de cultos, extinguiendo tanto el fuero eclesiástico como el derecho del clero para aplicar las penas temporales y dictaminó en favor de la absoluta independencia de Yucatán en virtud de haber sido violado por México el pacto federal. ${ }^{34}$

En Mérida, Thompson logró entre. vistarse con las autoridades, a las cuales les propuso lo que había planeado para la ciudad de México. Sin embargo, el obispo de Yucatán se opuso a tal acción y logró aplazarla, con lo cual ganó un tiempo precioso ya que, más adelante, Yucatán decidió regresar a formar parte de México, con lo cual perdió la libertad religiosa que había proclamado. ${ }^{35}$ Thompson, así las cosas, no ve ya más alternativas para su trabajo que regresar a Inglaterra, en 1844.

En 1847 la BFBs le encargó hacer trabajos en España, Portugal, Francia y Marruecos, siempre teniendo como base a España; en 1849 regresó a Londres y comunicó a la BFBS su deseo de ya no colaborar como colporteur. En 1852 escribió un libro titulado: Nottces respecting missionary operations and religious liberty in Portugal, Spain and South America. Y un año más tarde, Spain its positton and evangelization. Finalmente, murió en Londres en febrero de 1854.

En el informe de ese año de la BFBS se encuentra la siguiente noticia:

La Sociedad no puede recibir las noticias de la muerte de su querido amigo doctor James Thompson, quien de 1823

34 Alcalá, Historia, 1984, vol. v, p. 197. 35 Gandee, "Introduction", 1949, p. 73. 
a 1844 fue uno de sus agentes en el exterior, sin dejar asentado su reconocimiento por los valiosos y fieles servicios que durante ese largo tiempo él prestó en Sudamérica, las Antillas, América Británica y México, y en otros lugares, y recientemente, a petición de la Sociedad, se hizo cargo de una misión provisional en España. La Sociedad recuerda con especial aprecio la piedad personal del doctor Thompson, su espíritu libre de sectarismos, su devoción al trabajo, su celo, su tacto y su gran perseverancia en realizarlo. También se debe decir que desde que dejó de tener contacto oficial con la Sociedad, él ha estado continuamente interesado por la Sociedad y listo para servir a los países que fueron el escenario de sus actividades pasadas. Muchos son testigos de la gran ayuda voluntaria que dio mientras pudo hacerlo y siempre con la mayor satisfacción de las diferentes instituciones y proyectos cuyo objetivo fue la evangelización de todo el mundo, un propósito cercano a su corazón. ${ }^{36}$

¿Cuáles fueron los méritos de la labor de Thompson en nuestro país durante su estancia?

Gracias a su labor logró interesar a un grupo pequeño, pero influyente, en la necesidad de distribuir la $\mathrm{Bi}$ blia masivamente en México, además de promover la idea de traducirla a diversas lenguas. Indirectamente, motivó a la Iglesia católica a preocuparse más por la distribución de la Biblia, práctica hasta entonces poco común entre las autoridades eclesiásticas.

Su trabajo como colporteur lo llevó a visitar diversos puntos de la pro-

36 Browning, "Lancaster", 1921, p. 98. vincia mexicana, repartiendo gran número de biblias y literatura en general. Esta labor daría sus frutos años después, ya que sentó el antecedente más remoto de las futuras congregaciones protestantes. Además de que en su larga correspondencia con las sociedades debió haber informado de múltiples aspectos de la realidad mexicana, que seguramente ayudaron a que en Inglaterra se conociera más acerca de México; no hay que olvidar que sus cartas eran leidas por los socios, quienes en un buen porcentaje estaban dentro del gobierno británico. Aunque no fue el introductor original del sistema lancasteriano, su presencia y su trabajo lograron trascender, según lo demuestra el informe de Ro. cafuerte.

\section{BIBLIOGRAFÍA}

-Alcalá, Alfonso y otros, Historia general de la Iglesia en América Latina, Méxtco, vol. v, CEHILA Ediciones Paulinas, México, 1984.

-Báez Camargo, Gonzalo (seudónimo: Pedro Gringoire), El Dr. Mora impulsor nacional de la causa bíblica en México, Sociedades Bíblicas en América Latina, Mexico, s.a. (Historia, 1)

-Browning, W. E., "Joseph Lancaster, James Thompson and the lancasterian system of mutual instruction, with special reference to Hispanic America", The Hispanic American Historical Review, vol. Iv, núm. 1, febrero 1921, pp. 49-98.

-Dunstan, Leslie J. (comp.), Protestantism, George Braziller, Nueva York, 1961 (Great Religions of Modern Man).

-Encyclopaedia Britannica, vols. II, III y vII, Encyclopaedia Britannica Inc., Chicago, 1982. 
-Gandee, Lee, "The introduction and ninteenth century development of protestantism in Mexico", tesis de maestría, Mexico City College, México, 1949.

-Goslin, Tomás S., Los evangélicos en la América Latina, siglo $X I X$, los comienzos, La Aurora, Buenos Aires, 1956.

-Hale, Charles A., El liberalismo mexicano en la época de Mora (1821-1835), Siglo XXI Editores, México, 1978.

-Hastings, Nichols James, History of christianity, 1650-1950, secularization of the West, The Ronald Press Company, Nueva York, 1956.

-Macín Raúl, Lutero: presencia religiosa y política en México, Ediciones Nuevo Mar, México, 1983 (Religión y Política, 3).

-Mckechnic, Marian, "The mexican revolution and the national presbyterian church of Mexico, 1910-1940", tesis de doctorado, The American University Press, Washington, D.C., 1970.
-Ortega y Medina, Juan A., La evange. lización puritana en Norteamérica. Delendi sunt Indi, Fondo de Cultura Económica, México, 1976.

-Rocafuerte, Vicente, Las revoluciones de México, ensayo sobre tolerancia reltgiosa, Bibliófilos Mexicanos, México, 1962.

-Rodríguez O., Jaime E., El nacimiento de Hispanoamérica. Vicente Rocafuerte $y$ el bispanoamericanismo, 1808-1823, Fondo de Cultura Económica, México, 1980.

-Staples, Anne, La Iglesia en la primera republica federal mexicana (1824-1835), Secretaría de Educación Pública, México, 1976 (Sepsetentas, 237).

-Varetto, Juan C., Héroes y mártires de la obra misionera. Desde los apóstoles basta nuestros días, Junta de Publicaciones de la Convención Evangélica Bautista, Buenos Aires, 1958.

-Westrup, Horacio, Paladines del Evangelio en México, Buena Prensa, México 1953. 